\title{
Erratum to: Structural, optical and multiferroic properties of pure and Dy modified $\mathrm{YMnO}_{3}$
}

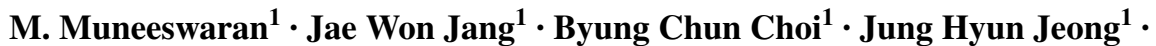 \\ N. V. Giridharan ${ }^{2}$
}

Published online: 19 September 2017

(c) Springer Science+Business Media, LLC 2017

\section{Erratum to: J Mater Sci: Mater Electron \\ DOI 10.1007/s10854-017-7593-z}

The original version of this article unfortunately contained a mistake in the corresponding author information. Jung Hyun Jeong is unfortunately omitted in the original version. Jung Hyun Jeong and N. V. Giridharan are the corresponding authors of the paper.

The online version of the original article can be found under doi:10.1007/s10854-017-7593-z.

Jung Hyun Jeong

jhjeong@pknu.ac.kr

$\triangle$ N. V. Giridharan

giri@nitt.edu

1 Department of Physics, Pukyong National University, Busan 48513, South Korea

2 Department of Physics, National Institute of Technology, Tiruchirappalli 620 015, India 